\title{
Desenvolvimento da Identidade em Adolescentes Estudantes do Ensino Médio
}

\author{
Identity Development in Brazilian Adolescents
}

\author{
Teresa Helena Schoen-Ferreira ${ }^{*}, a$, Maria Aznar-Farias ${ }^{a}, \&$ Edwiges Ferreira de Mattos Silvares ${ }^{b}$ \\ ${ }^{a}$ Universidade Federal de São Paulo \& ${ }^{b}$ Universidade de São Paulo
}

\begin{abstract}
Resumo
Identidade é composta pelos valores, crenças e metas com que um indivíduo está comprometido. Existem quatro estados de identidade: difusão, pré-fechamento, moratória e identidade estabelecida, identificados de acordo com a presença de exploração das alternativas e com a intensidade dos compromissos. Este trabalho verificou os estados de identidade em que se encontravam 753 adolescentes de 15 a 18 anos, estudantes do Ensino Médio de escolas públicas de São Paulo que responderam ao EOMEIS 2, uma escala tipo Likert que avalia os estados de identidade. A maioria dos adolescentes encontrava-se em moratória. Verificou-se uma associação positiva entre o sexo feminino e os estados de moratória e identidade estabelecida; entre a primeira série do Ensino Médio e o estado de pré-fechamento.

Palavras-chave: Identidade do ego; Adolescência; EOMEIS 2.
\end{abstract}

\begin{abstract}
Identity is composed by values, beliefs and goals to which an individual is committed. There are four states of identity determined according to the exploration of alternatives and the intensity of commitment: diffusion, foreclosure, moratorium and achievement. This work evaluated the identity states of 753 Brazilian adolescents from 15 to 18 years old who study in public schools in the city of São Paulo. They responded to the Extended Objective Measure of Ego Identity Status (EOMEIS 2) a kind of Likert scale that measures states of identity. Most adolescents were in moratorium state. A positive association was identified between the female gender and both the states of moratorium and achievement, as well as, between the first year of high school and foreclosure.

Keywords: Ego identity; Adolescence; EOMEIS 2.
\end{abstract}

Construir uma identidade, para Erikson (1972), implica definir quem a pessoa é, quais são seus valores e quais direções deseja seguir pela vida. Ele entende que identidade é uma concepção bem organizada do ego, composta de valores, crenças e metas com os quais o indivíduo está solidamente comprometido.

De acordo com a teoria Psicossocial de Erikson (1972, 1998), existem dois pólos na formação da identidade, resultantes do confronto de forças antagônicas: identidade do ego - pólo positivo - e difusão de identidade pólo negativo. O pólo positivo - identidade - acontece quando os jovens escolhem os valores aos quais serão fiéis, tornando-se, então, conscientes de sua uniformidade e continuidade no tempo e no espaço, e percebendo que suas realizações possuem reconhecimento e significado em sua cultura (Erikson, 1979).

Erikson (1972) considera a difusão de identidade como o início do processo de construção da identidade ou a resultante negativa no desenvolvimento. Isto acontece

* Endereço para correspondência: Universidade Federal de São Paulo, Centro de Atendimento e Apoio ao Adolescente, Rua Botucatu, 715, Vila Clementino, São Paulo, SP, Brasil,CEP04015-011.E-mail: teresaschoen.dped@epm.br quando o indivíduo tem dificuldades em aprender sobre si mesmo e seu entorno, não conseguindo construir uma identidade que seja realista em consonância com suas características pessoais e de seu contexto sócio-cultural.

$\mathrm{Na}$ transição da adolescência, a sociedade estabelece um período de postergação das responsabilidades, para a tomada de consciência das duas percepções - si mesmo e entorno -, ao qual Erikson $(1972,1998)$ denominou de moratória. As culturas providenciam situações institucionalizadas onde os indivíduos podem se identificar com outros e se preparar para os papéis adultos (Adams, 1998; Lavoie, 1994). Entretanto, a sociedade do conhecimento dificulta o processo de formação de identidade pelos adolescentes, pois combina um amplo repertório de possibilidades com uma falta de base sólida sobre a qual o indivíduo vai escolher suas opções (Zacarés, 1996).

Identidade, como estrutura psicossocial, é um sistema de auto-regulação, que dirige a atenção, filtra ou processa as informações, gerencia as impressões e seleciona os comportamentos apropriados (Adams, 1998). Ela é sempre construída num contexto relacional (Lavoie, 1994).

O trabalho de Marcia (1966) sistematiza a teoria Psicossocial de Erikson. Apresenta como base explicativa 
do processo da formação da identidade duas dimensões independentes, porém essenciais: exploração e comprometimento. As questões que preocupam o jovem (que serão exploradas e com as quais se comprometerá ou não) podem levá-lo por diferentes caminhos (Vleioras \& Bosma, 2005). A estes diferentes caminhos ou maneiras de se desenvolver para ser adulto, Marcia (1966) denominou estados de identidade. Os quatro estados são: difusão, pré-fechamento, moratória e identidade estabelecida. Os indivíduos são classificados em um determinado estado de identidade de acordo com a presença de exploração das alternativas e com a intensidade com que se comprometem com uma delas. Cada estado representa um nível específico de exploração e de compromisso; é uma modalidade particular de dirigir-se dentro da dinâmica do processo de construção da identidade (Schwartz, 2004). Os modelos de estágios de desenvolvimento propõem sequiências evolutivas que conduzem os sujeitos a estruturas qualitativamente superiores mais maduras (Zacarés \& Serra, 1998).

Difusão é caracterizada pela não assunção de compromissos e não exploração de alternativas. Pré-fechamento é caracterizado pelo comprometimento sem um período prévio de exploração. Estes dois estados são considerados por Marcia (1966) iniciais no processo de construção da identidade. Moratória é caracterizada pela exploração de alternativas, porém com baixos níveis de comprometimento. Identidade estabelecida é caracterizada pela assunção de compromissos após um período de exploração (moratória).

A identidade deve ser considerada como um construto multidimensional (Meeus, 1993). Erikson (1972) considerava o sistema de crenças religiosas e políticas particularmente importantes no desenvolvimento da identidade, por estabelecer uma visão de mundo que facilita a harmonização entre os diversos temas a serem explorados. Ao enfocar a adolescência, Marcia (1966) considerou-a como o período do ciclo da vida onde a escolha profissional e o comprometimento ideológico são questões preponderantes, pois estão intimamente relacionadas com a entrada na vida adulta, onde o indivíduo irá desempenhar uma ocupação e exercer seu papel de cidadão.

Embora não seja assim com todos, o início do processo de construção da identidade acontece na metade final do período da adolescência (Kimmel \& Weiner, 1998; Stephen, Fraser, \& Marcia, 1992). A adolescência é um período de parada para autodescoberta e avaliação. Assumir os compromissos requer habilidades para procurar ou gerar opções, considerar as conseqüências, prever os obstáculos e planejar como executar suas escolhas. Os indivíduos necessitam elaborar e integrar suas capacidades cognitivas, sociais, emocionais e corporais. A moratória é exatamente o período em que a pessoa integra os conhecimentos e experiências para, por fim, comprometer-se com algum deles.

Segundo Matteson (1992), na adolescência não ocorre um único momento de exploração. Os jovens vão se confrontando com diversas alternativas, no princípio da adolescência, mais voltadas às mudanças corporais e, no final, mais voltadas às ideologias. Em cada época que se medir o estado de identidade pode haver mudanças no mesmo indivíduo que está em desenvolvimento. Stephen et al. (1992), inclusive, afirmam que o processo de formação de identidade é contínuo, sucedendo períodos de exploração e comprometimento ou ciclos MAMA (Moratorium-Achievement-MoratoriumAchievement - moratória-identidade estabelecida-moratória-identidade estabelecida).

Os adolescentes, ao desenvolverem-se cognitiva e socialmente, estão mais propensos a reconhecer que existem muitos caminhos possíveis além dos trilhados por seus pais. Adquirem a capacidade de pensar no que poderia acontecer, podem imaginar como poderiam ser as coisas, sem necessitar testar todos os caminhos ou alternativas. Podem supor futuras tarefas, escolhas e possibilidades. Desenvolvem a capacidade de perceber que a realidade é apenas uma entre muitas situações possíveis (Sprinthall \& Collins, 1999). Apresentam um pensamento mais abstrato, especulativo e flexível. E também adquirem a capacidade de reconhecer que diferentes pessoas podem ter diferentes pensamentos ou opiniões sobre uma mesma situação. $\mathrm{O}$ caráter mais abstrato e a maior complexidade do pensamento dos adolescentes significam que possuem capacidade para perceberem e considerarem simultaneamente um maior número de aspectos das situações e relações sociais. Também são capazes de desenvolver conceitos complexos e abstratos sobre si próprios e sobre as outras pessoas. Compreendem que os indivíduos podem formar perspectivas uns sobre os outros em diferentes níveis - desde trocar informações, compartilhar interesses superficiais a dividir valores ou opiniões comuns a respeito de idéias bastante abstratas de natureza religiosa, moral, política ou social.

Erikson (1972) afirma que o desenvolvimento da identidade é universal, podendo haver variações nas interações sociais de cultura para cultura, mantendo-se dentro de um "ritmo apropriado e na seqüência adequada que governa toda a epigênese" (p. 92). O curso da vida individual deve ser entendido no contexto de uma comunidade em permanente mudança.

Estudos americanos (Bergh \& Erling, 2005; Sprinthall \& Collins, 1999; Waterman, 1985) encontraram como estado prevalente, nesta faixa etária, o de moratória. O mesmo vem acontecendo com estudos em outras culturas. Na Turquia, o estado prevalente em todas as faixas etárias foi o de moratória (Kumru \& Thompson, 2003). Observou-se um acréscimo da porcentagem de adolescentes em moratória e identidade estabelecida em relação ao aumento da idade e um declínio em relação aos estados de pré-fechamento e difusão de identidade associado com o aumento da idade.

Branch, Tayal e Triplett (2000), estudando os estados de identidade em americanos negros, observaram que havia uma porcentagem maior de estudantes em identidade estabelecida nas séries mais avançadas tanto no 
domínio ideológico quanto no domínio interpessoal. Entretanto, o estado predominante, independentemente da série escolar, era moratória.

Pesquisas nesta área vêm encontrando diferenças entre os sexos. Cakir e Aydin (2005) observaram, em seu estudo desenvolvido na Turquia, que as adolescentes do sexo feminino encontravam-se mais em identidade estabelecida, enquanto que adolescentes do sexo masculino mais em pré-fechamento. Bergh e Erling (2005) observaram que as jovens suecas encontravam-se mais em identidade estabelecida e moratória, que os rapazes suecos.

Diferentemente da América do Norte e Europa, não existem pesquisas empíricas brasileiras sobre os estados de identidade. Embora o conceito não seja desconhecido no Brasil, muito pelo contrário, é um construto bastante difundido, os trabalhos brasileiros não se baseiam na teoria Psicossocial de Erikson e nem nos estudos de Marcia. Grande parte dos trabalhos baseia-se na teoria psicanalítica, na fenomenologia e na identidade vocacional de Boholawsky, geralmente estudando algum grupo específico (adolescentes grávidas ou delinqüentes) ou alguma área (ocupacional, étnica, cidadania). A partir desse levantamento, julgou-se oportuno estudar-se o desenvolvimento da identidade no adolescente brasileiro, com dados objetivos que pudessem ser replicáveis e que permitam uma melhor correlação com as áreas já estudadas, como problemas de comportamento, etnia, gravidez, escolha da profissão ou cidadania.

O objetivo do presente estudo foi verificar os estados de identidade em que se encontram adolescentes brasileiros que estudam no Ensino Médio.

\section{Método}

\section{Participantes}

Participaram deste estudo 753 estudantes do Ensino Médio de duas escolas públicas da região sul do município de São Paulo, que por terem sua qualidade reconhecida no meio acadêmico, recebem alunos de toda a cidade e de municípios circunvizinhos, sendo $357(47,41 \%)$ do sexo masculino e 396 (52,59\%) do sexo feminino; com idade que variou de 15 a 18 anos. Não houve diferença proporcionalmente significativa entre os sexos $(p$ $=0,232$ ), verificada através do Teste de Igualdade de Duas Proporções. A distribuição de adolescentes por sexo, em nossa amostra, é semelhante a da população brasileira.

\section{Instrumento}

O Extended Objective Measure of Ego-Identity Status ([EOMEIS-2]; Bennion \& Adams, 1986) é uma escala de origem norte-americana, com validação em diversos países (Bergh \& Erling, 2005; Dwairy, 2004; Matos, Barbosa, Almeida, \& Costa, 1999; Tremblay, Saucier, \& Tremblay, 2004), o que facilita a comunicação dos resultados, destacando-se como o instrumento de estudos so- bre identidade mais citado na literatura internacional. É uma escala auto-aplicável, que demora em torno de 20 minutos para seu total preenchimento. O questionário compreende 64 afirmações que abrangem os domínios Ideológico e Interpessoal (quatro áreas em cada), sendo oito afirmações para cada área (duas para cada estado de identidade). (a) Áreas da escala do domínio Ideológico: Ocupacional: a questão central desta área é tomar uma decisão sobre o trabalho a assumir para o seu futuro; Religião ou crenças religiosas: esta área refere-se ao modo e à profundidade com que o sujeito vem elaborando seus pontos de vista sobre temas que geralmente se consideram religiosos; Política: esta escala avalia a relação entre o indivíduo e a sociedade em que vive; Filosofia de vida: esta área refere-se ao sistema de crenças que utilizam os sujeitos em seu modus operandi, estabelecendo uma relação nos modos de processamento que o indivíduo utiliza para o seu fazer cotidiano. (b) Áreas da escala do domínio Interpessoal: Lazer ou tempo livre: mede a relação do indivíduo com atividades no tempo livre (esportes, atividades extracurriculares); Amizade: estuda como o indivíduo se define em relação a seus amigos; Papel de gênero: consiste em determinar o que significa para o sujeito ser homem ou mulher, especialmente dentro do matrimônio; Relacionamento amoroso: esta área refere-se a todas as possíveis relações entre parceiros amorosos.

O somatório das respostas assinaladas pelo indivíduo permite ao pesquisador traçar o estado de identidade em cada um dos domínios em que estava no momento em que respondeu a escala. Cada uma das afirmações reflete características de um dos quatro estados de identidade: 16 fazem referência a Identidade Estabelecida ("Há muitas razões para uma amizade. Escolho meus melhores amigos de acordo com certos valores e semelhanças entre nós.”); 16, a Moratória ("Estou procurando descobrir quais as minhas habilidades e interesses vocacionais e tentando definir o que quero para meu futuro em termos de profissão"); 16, a Difusão ("Eu ainda não escolhi o que quero fazer na vida em termos profissionais. Vou fazendo qualquer coisa até que encontre algo melhor."); e outras 16, a Pré-fechamento ("As minhas idéias a respeito dos papéis masculino e feminino são fortemente influenciadas pelas de meus pais.”). Os adolescentes valoram cada item em uma escala tipo Likert de 6 pontos, desde discordo totalmente até concordo totalmente.

A versão utilizada neste estudo foi a adaptação brasileira do EOMEIS 2, por Schoen-Ferreira, Meneghelli, Veiga-Godoy e Aznar-Farias (2005). Adams (1998) e Adams e Marshalll (1996) recomendam que estes dois domínios sejam analisados separadamente.

\section{Procedimento}

Após a aprovação do estudo pelo Comitê de Ética em Pesquisa, foi feito contato com o autor da EOMEIS 2, para o uso desta escala no Brasil. Foi solicitada autoriza- 
ção para aplicação do instrumento em duas escolas públicas da cidade de São Paulo. Os alunos responderam ao instrumento em sala de aula, em horário regular de estudo cedido pelo professor.

\section{Análise dos Dados}

Para análise dos dados foram utilizados o teste Quiquadrado e o Teste de Igualdade de duas Proporções.

\section{Resultados}

O estado que prevaleceu, em ambos os domínios, foi o de moratória, com 54,1\% dos adolescentes no domínio Ideológico e 59,6\% no domínio interpessoal, seguido de difusão de identidade (18,1\% e 15,5\%); pré-fechamento $(15,0 \%$ e $13,7 \%)$; e identidade estabelecida $(12,9 \%$ e $11,2 \%)$. No geral, estes três últimos estados não se distanciaram muito entre si em relação ao número de adolescentes classificados neles, demonstrando claramente a prevalência da moratória nesta faixa etária.

As adolescentes do sexo feminino apresentaram-se mais em moratória e identidade estabelecida, e os meninos mais em pré-fechamento e difusão de identidade.

Tabela 1

Distribuição, em Porcentagem, dos Alunos, por Sexo, nos Estados de Identidade no Domínio Ideológico e Interpessoal

\begin{tabular}{lllll}
\hline \multirow{2}{*}{ Estado de identidade } & \multicolumn{2}{c}{ Ideológico } & \multicolumn{2}{c}{ Interpessoal } \\
\cline { 2 - 5 } & Masc & Fem & Masc & Fem \\
\hline Moratória & $46,2 \%$ & $61,1 \%$ & $54,3 \%$ & $64,4 \%$ \\
Identidade Estabelecida & $10,9 \%$ & $14,6 \%$ & $9,2 \%$ & $12,9 \%$ \\
Difusão & $23,5 \%$ & $13,1 \%$ & $21,6 \%$ & $10,1 \%$ \\
Pré-fechamento & $19,3 \%$ & $11,1 \%$ & $14,8 \%$ & $12,6 \%$ \\
Total & $47,4 \%$ & $52,6 \%$ & $47,4 \%$ & $52,6 \%$ \\
\hline
\end{tabular}

Nota. $p<0,001$.

Interessante ressaltar que neste estudo, embora haja mais mulheres que homens em moratória ou identidade estabelecida em ambos os domínios, a distância entre os sexos foi maior no domínio Ideológico, e não no domínio Interpessoal.

Foi feita a comparação dos percentuais por sexo, nos dois domínios (Ideológico e Interpessoal). Para tanto, utilizou-se o teste de Igualdade de Duas Proporções. Somente nos adolescentes do sexo masculino existiu uma diferença entre os domínios considerada estatisticamente significante. Houve mais rapazes em moratória no domínio Interpessoal que no domínio Ideológico. Para as moças não houve diferença na distribuição da amostra por domínio, o percentual em cada estado é semelhante.

Não houve associação significativa no tocante à idade dos adolescentes em relação aos estados de identidade, tanto no domínio Ideológico $(p=0,659)$, quanto no domínio Interpessoal $(p=0,322)$. Em todas as idades, moratória continua sendo o estado prevalente. Embora não tenha sido estatisticamente significante, há um aumento da presença de adolescentes em identidade estabelecida com a idade, no domíno Interpessoal. Não houve diferença entre os percentuais das faixas de 14 e 18 anos, seja no domínio Ideológico ou Interpessoal, embora tivesse sido encontrada uma tendência, nos adolescentes mais velhos, para identidade estabelecida, em relação aos mais novos no domínio Interpessoal.
Observou-se mais adolescentes em pré-fechamento aos 14 anos, em ambos os domínios, que nas outras idades. Parece que nossos adolescentes iniciam os seu processo de construção da identidade no estado de pré-fechamento, ou seja, partem dos valores familiares para os questionamentos sobre quem são e qual o seu papel na sociedade.

Foi observada a distribuição dos adolescentes nas três séries do Ensino Médio (Tabelas 2 e 3), pois cada uma delas deve contribuir com alguma parcela, tanto para o desenvolvimento do raciocínio, como para compreensão do mundo, através das diversas disciplinas e atividades escolares.

Não houve associação estatística significativa em relação ao estado de identidade e a série escolar. Moratória é o estado de identidade com mais alunos, independente da série. Compararam-se as séries escolares $\left(1^{\mathrm{a}}\right.$ e $2^{\mathrm{a}}$ séries), também em cada um dos estados, nos domínios Ideológico e Interpessoal. Em ambos os domínios houve uma associação estatisticamente significativa entre série e pré-fechamento, indicando que os alunos da $1^{\mathrm{a}}$ série do Ensino Médio encontravam-se mais em pré-fechamento, que os alunos da $2^{\mathrm{a}}$ série, e uma tendência para mais adolescentes em identidade estabelecida nesta série. No domínio Ideológico, moratória teve um $p=0,394$; identidade estabelecida, $p=0,201$; difusão, $p=0,970$; $\mathrm{e}$ pré-fechamento, $p=0,026$. No domínio Interpessoal, moratória teve um $p=0,553$; identidade estabelecida, um $p=0,082$; difusão, $p=0,966$; e pré-fechamento, $p=0,017$. 
Tabela 2

Distribuição, em Porcentagem, dos Alunos, por Série, Estados de Identidade no Domínio Ideológico

\begin{tabular}{lllll}
\hline Estado de identidade & $1^{\text {a }}$ série & $2^{\mathrm{a}}$ série & $3^{\mathrm{a}}$ série & Total \\
\hline Moratória & $51,2 \%$ & $54,9 \%$ & $56,8 \%$ & $54,1 \%$ \\
Identidade estabelecida & $10,7 \%$ & $14,3 \%$ & $14,1 \%$ & $12,9 \%$ \\
Difusão & $17,8 \%$ & $17,7 \%$ & $18,9 \%$ & $18,1 \%$ \\
Pré-fechamento & $20,3 \%$ & $13,2 \%$ & $10,2 \%$ & $15,0 \%$ \\
Total & $37,3 \%$ & $35,3 \%$ & $27,4 \%$ & $100,0 \%$ \\
\hline
\end{tabular}

Nota. $p=0,073$.

Tabela 3

Distribuição, em Porcentagem, dos Alunos, por Idade, Estados de Identidade no Domínio Interpessoal

\begin{tabular}{lllll}
\hline Estado de identidade & $1^{\text {a }}$ série & $2^{\text {a }}$ série & $3^{\text {a }}$ série & Total \\
\hline Moratória & $57,7 \%$ & $60,2 \%$ & $61,7 \%$ & $59,6 \%$ \\
Identidade estabelecida & $8,5 \%$ & $13,2 \%$ & $12,1 \%$ & $11,2 \%$ \\
Difusão & $15,7 \%$ & $15,8 \%$ & $15,0 \%$ & $15,5 \%$ \\
Pré-fechamento & $18,1 \%$ & $10,9 \%$ & $11,2 \%$ & $13,7 \%$ \\
Total & $37,3 \%$ & $35,3 \%$ & $27,4 \%$ & $100 \%$ \\
\hline
\end{tabular}

Nota. $p=0,134$.

\section{Discussão}

Semelhante aos resultados encontrados em outros trabalhos (Bergh \& Erling, 2005; Sprinthall \& Collins, 1999; Waterman, 1985), a maioria dos adolescentes deste estudo foram classificados em moratória. Este resultado diferiu do encontrado por Bishop, Weisgram, Holleque, Lund e Wheeler-Anderson (2005) e por Schoen-Ferreira, Aznar-Farias e Silvares (2003), que obtiveram como estado predominante na sua amostra, difusão de identidade. Acreditamos que esta diferença deva-se às características demográficas da amostra, que foi composta, no primeiro estudo por adolescentes de escola particular, onde as exigências sociais descartam compromissos firmes nesta faixa etária. O contexto social e histórico dos indivíduos proporciona a pressão necessária para deflagrar o processo de construção da identidade. Alguns contextos cozinham a fogo lento a assunção de papéis adultos (Erikson, 1972).

As conseqüências de muitas escolhas feitas na adolescência podem durar o resto da vida. A moratória psicológica constitui-se em importante variável mediadora para a resolução das tarefas evolutivas, não só presentes, como também futuras, permitindo que o desenvolvimento possa avançar para níveis superiores de maturidade.

Dois terços dos estudantes (moratória + identidade estabelecida) parecem ser capazes de realizar o trabalho psicológico exigido para uma estruturação pormenorizada da identidade, enquanto que em torno de um terço dos estudantes (difusão + pré-fechamento) ainda não é capaz. Alguns adolescentes são confrontados simulta- neamente, com vários desafios à construção da identidade, quando as tensões pessoais e situacionais tornam mais difíceis a superação dos obstáculos.

As estudantes do sexo feminino encontraram-se nos estados mais maduros do processo de construção da identidade. Resultado semelhante foi encontrado por Bergh e Erling (2005). Uma das razões para isso ocorrer pode estar em função das diferenças de início da puberdade. As adolescentes do sexo feminino ingressam na puberdade em média dois anos antes que os rapazes (Hoffman, Paris, \& Hall, 1997; Kimmel \& Weiner, 1998). Os efeitos da puberdade influenciam as interações do adolescente com sua família e colegas. As modificações corporais ocorridas levam o adolescente a ter um corpo de adulto e acabam interferindo nas relações interpessoais, pois servem como um indicador de maturidade. Os pais começam a tratar o filho de acordo com seu corpo, conversando com ele questões mais profundas e delegando responsabilidades que, acreditam, aquele jovem tenha condições de suportar. Desta forma, o fato da mulher amadurecer fisicamente antes que o homem influencia no seu processo de amadurecimento psicossocial. Por ter já um corpo adulto, somado aos efeitos dos hormônios sexuais, ela se vê defrontada com questões relativas ao relacionamento entre pares, ao relacionamento amoroso, às divisões das tarefas domésticas e à perspectiva de futuro, antes dos rapazes.

A construção da identidade incorpora todos os direitos e deveres que foram constituídos durante a evolução da humanidade, a ponto de, hoje, as pessoas nem se darem conta de que alguns comportamentos tão óbvios neces- 
sitaram ser arduamente consquistados: o voto feminino, a alfabetização universal, o direito ao lazer, o direito a escolher uma profissão ou o direito a escolher um companheiro.

A emancipação da mulher foi adquirindo um significado cada vez mais amplo ao longo dos séculos. No final do século XIX, algumas queriam, além do respeito, tratamento favorável dentro da família e direito à educação, assim como o pleno desenvolvimento, dentro e fora do lar. Não obstante, ainda hoje alguns desses direitos não são reconhecidos e exercidos igualmente em todas as famílias ou classes sociais.

Quando o indivíduo chega à adolescência, é confrontado com novos papéis, oportunidades e responsabilidades (Sprinthall \& Collins, 1999). É um leque que se abre. As jovens exploram e tomam suas decisões antes dos rapazes e, nem sempre, as decisões esperadas para os adolescentes do sexo masculino são estimuladas nas moças. Embora este seja um estudo transversal, e possa dar a impressão de que os adolescentes estão estáticos em um dos estados de identidade, a complexidade do mundo contemporâneo pressiona o jovem a pensar a respeito de sua posição no mundo.

Pelos resultados deste estudo, os adolescentes partem dos valores familiares para enfrentarem a tarefa da construção da identidade. Os valores universais independem do tempo e do espaço. Tanto Erikson $(1972,1979)$, quanto outros autores, como Isquierdo (2002), dizem que o adulto tem a obrigação de transmitir às gerações mais novas os valores que as ajudem a amadurecer e a colaborar com a sociedade. Pais e educadores não devem se omitir em sua missão de ensinar valores universais, para que estes jovens possam estar implicados com o seu próprio desenvolvimento físico, cognitivo, moral e social e com o de seu grupo social. A nova geração precisa de uma base firme para viver outras experiências e explorar as novas maneiras de ser na sociedade do conhecimento e, então, construir sua própria escala de valores e princípios, na qual irá basear sua conduta futura.

Para as crianças, os pais e professores são uma fonte de informação sobre os princípios e valores do grupo social. Para os adolescentes, estes adultos devem transformar-se em pontos de apoio para a exploração, não só da escala de valores, mas das conseqüências em se optar por seguir um ou outro princípio.

Quase um quarto dos adolescentes de 18 anos encontrava-se em difusão de identidade no domínio ideológico. Nesta idade o adolescente é cobrado para atuar, em muitas questões, como se já fosse um adulto. É uma idade marco para muitas exigências da sociedade moderna, as quais não são suficientemente acompanhadas de apoio para serem enfrentadas. De um lado, existe a exigência social para ingresso no mercado de trabalho; por outro, há uma falta de perspectiva em relação ao futuro profissional. De um lado, existe a obrigação de se registrar como eleitor e votar nas eleições; de outro, as incertezas e desinformações que permeiam as decisões relativas ao campo político. Para estes adolescentes, política é sinônimo de corrupção. As esperanças depositadas em alguns candidatos ruíram quando estes tiveram que lidar com o poder e a problemática brasileira. Experiências escolares neste campo são poucas e muitas vezes associadas ao autoritarismo e questões supérfluas.

Erikson (1979) afirma que os políticos devem personalizar os ideais da Nação. Escreve ainda que, referindo-se aos Estados Unidos, como isto não está acontecendo, não é de admirar que os jovens estejam desenvolvendo uma identidade difusa. Afirma, ainda, que existe uma certa abdicação de responsabilidades por parte dos adultos, inclusive em fornecer ideais convincentes (Erikson, 1972).

O mesmo pode estar ocorrendo com nossos jovens: as dificuldades em entender e desenvolver um compromisso com um sistema de idéias que proporcione uma imagem do mundo, inclusive em relação ao tema política. A falta de compreensão dos contextos em que os indivíduos estão inseridos, tanto política quanto socialmente, interfere na construção da identidade. Este processo depende da experiência que possuem nestes campos. A vida acadêmica pode colaborar, ao permitir que seus adolescentes participem de grêmios estudantis, centros acadêmicos ou mesmo de algumas decisões na escola. Entretanto, cada vez menos observamos a participação de estudantes em atividades de interesse coletivo: tanto há barreiras colocadas pela direção das escolas, quanto não há interesse dos alunos em tomar parte dos assuntos administrativos. O estado de difusão de identidade pode ser a conseqüência de, ao serem confrontados com a realidade, não conseguirem resolver adequadamente os tópicos que envolvem este domínio.

$\mathrm{Na}$ adolescência os indivíduos devem tomar consciência de que as pessoas seguem, freqüentemente, códigos comportamentais que são bastante diferentes das normas oficiais e dos valores que a sociedade estabelece. Aquilo que as pessoas dizem muitas vezes diferem do que fazem. O adolescente, além de conhecer os valores, precisa conhecer a situação que motiva os comportamentos: em consonância ou não com os princípios expressos pelos indivíduos. É um trabalho psicológico bastante complexo, e alguns adiam ao máximo esta análise de princípios e fatores; outros nem conseguem fazê-lo, e desistem. Tanto esses, quanto aqueles, acabam por se encontrar em difusão de identidade.

Aos 18 anos, no domínio interpessoal, o segundo estado onde mais se encontram os adolescentes é o pré-fechamento. Alguns adolescentes podem estar tão identificados com as figuras paternas que acham desnecessário explorar este domínio.

A capacidade para compreender a complexidade e o significado das situações e interações sociais sofre alterações à medida que os adolescentes vão se tornando cognitivamente mais desenvolvidos. Porém, alguns adolescentes continuam utilizando o mecanismo de identi- 
ficação, que foi necessário na infância. Tomar a responsabilidade dos relacionamentos interpessoais para si pode ser uma tarefa grande demais para estes adolescentes. Mirar-se nos adultos que são significativos e que conquistaram algum sucesso neste campo, talvez seja mais simples e demande menos trabalho psicológico, especialmente em uma época onde os relacionamentos sociais adquiriram novas formas e, muitas vezes, são bastante perturbadores e repletos de ambigüidade.

Reconhecer dentro de si mesmo os diferentes, reconhecer que não se é perfeito e assumir a sua não-onisciência, exige uma estrutura psíquica bastante forte e flexível, capaz de suportar conviver com a própria fragilidade. O jovem pode não ter força suficiente para tornar-se autônomo e, então, acomodar-se no estado de pré-fechamento.

Como em outros estudos (Schoen-Ferreira et al., 2003), este resultado indica que o processo de construção da identidade do ego é bastante longo. É necessário tempo para o adolescente identificar quais serão os valores e crenças, refletir a respeito e, só então, se comprometer com algum. Por isso o final do processo de construção da identidade - a assunção de compromissos - adentra o estágio do adulto jovem.

Comprometimento não é apenas uma fïme decisão sobre as diversas áreas que formam a identidade. Também é a presença de atividades dirigidas à implementação desta escolha. Observa-se, hoje, na sociedade do conhecimento, uma tendência ao descompromisso. Não é fácil viver no dia-a-dia os princípios com os quais a pessoa está se comprometendo, principalmente porque muitos desses princípios são difíceis de serem definidos. Ao mesmo tempo em que há um aumento na liberdade de escolha e nas opções, há também diminuição das restrições e pressões sociais a respeito das trajetórias da vida adulta que se pode seguir. Da mesma forma que se enfatiza a individualidade e o conhecer-se a si mesmo, não fica claro do que se trata este autoconhecimento e como conseguir a individuação (Zacarés, 1996). Com toda a tecnologia atual e dentro do período histórico que o jovem vive, é necessário que se aproprie do conhecimento existente - tanto sobre o mundo social, quanto sobre si - e se torne um ser maduro, e não apenas alguém mais velho.

$\mathrm{O}$ interesse pelo futuro aumenta com a idade, assim como o conhecimento das possibilidades. Os adolescentes mais velhos são mais realistas. Preocupam-se mais acerca das oportunidades profissionais, sabem e querem saber mais sobre trabalho e profissão. $\mathrm{O}$ interesse pode estar relacionado com as oportunidades de planejar que apresentam os acontecimentos da vida, como ir à escola, à universidade, namorar, trabalhar.

Para assumir algum compromisso, o adolescente precisa colocar em ação uma série de habilidades, destrezas, conhecimentos e valores que amealhou no decorrer de seu desenvolvimento. Cada tarefa, além das características do indivíduo, necessita uma abordagem diferente e possui conseqüências diversas. $\mathrm{O}$ adolescente precisa de flexibilidade para abordar os dilemas que o assolam.

A identidade integra as idéias e experiências passadas do indivíduo com as suas expectativas em relação ao presente e ao futuro. A capacidade cognitiva do adolescente para compreender e pensar acerca de si mesmo, dos outros e das suas experiências, desempenha um papel extremamente importante na aquisição de um sentido de coerência entre as atitudes e os comportamentos da pessoa ao longo do tempo e nos diferentes contextos.

Observa-se nesta amostra que os adolescentes do sexo masculino estão explorando mais o domínio Interpessoal que o domínio Ideológico - não que as meninas não o tenham feito, talvez já tenham ultrapassado esta fase. Relacionamento amoroso, relacionamento entre os pares, família e papel de gênero parece ser um assunto que ocupa mais os rapazes que política, religião, trabalho e lazer.

Em ambos os domínios, foram encontradas diferenças significativas dos percentuais das duas primeiras séries para pré-fechamento. A entrada no Ensino Médio parece ser um fator desencadeante de modificação no estado de identidade - assim como alguns estudos mostraram ser o ingresso na universidade (Lewis, 2003; Waterman, 1985). Observou-se uma diminuição significativa de indivíduos em pré-fechamento na $2^{\mathrm{a}}$ série em relação à $1^{\mathrm{a}}$. Os adolescentes utilizam-se das habilidades sociais, acadêmicas e cognitivas desenvolvidas ao longo do Ensino Fundamental para refletir a respeito de sua nova posição na escola do Ensino Médio e sobre este novo mundo que está se abrindo para ele. Podemos supor que o auto-descobrimento (Schwartz, 2002), como meio de promoção do desenvolvimento da identidade, ocorrerá naturalmente com maior frequiência num contexto educacional. Este favorece a exploração, já que os jovens estão expostos a novas opções de estilo de vida. Embora não seja objetivo específico do Ensino Médio, o jovem pode ir descobrindo com quais opções ele mais se identifica. Foi grande o número de indivíduos que deixaram o estado de pré-fechamento, ingressando no de moratória neste estudo. Outros adolescentes, que já estavam em moratória, puderam ingressar no estado de identidade estabelecida no domínio Interpessoal, tamanho é o impacto que a mudança de nível escolar provoca no desenvolvimento da identidade do ego.

Entretanto, em todas as séries houve alunos em préfechamento. O que demonstra que o Ensino Médio não é o único fator desencadeador da exploração. Características pessoais também agem em conjunto para empurrar o jovem para fases superiores do desenvolvimento.

Diversos estudos de acompanhamento vem observando que a realização bem sucedida da identidade conduz o indivíduo para a um bom desempenho das tarefas da vida adulta. 


\section{Referências}

Adams, G. R. (1998). Objective measure of ego identity status: A reference manual. Unpublished manuscript, University of Guelph, Ontário, Canadá.

Adams, G. R., \& Marshall, S. K. (1996). A developmental social psychology of identity: Understanding the personin-context. Journal of Adolescence, 19, 429-442.

Bennion, L. D., \& Adams, G. R. (1986). A revision of the extended version of the Objective Measure of Ego Identity Status: An identity instrument for use with late adolescents. Journal of Adolescent Research, 1, 183-198.

Bergh, S., \& Erling, A. (2005). Adolescent identity formation: A swedish study of identity status using the EOMEIS 2. Adolescence, 40, 377-396.

Bishop, D. I., Weisgram, E. S., Holleque, K. M, Lund, D. E., \& Wheeler-Anderson, J. R. (2005). Identity development and alcohol consumption: Current and retrospective selfreports by college students. Journal of Adolescence, 28(4), 523-533.

Branch, C. W., Tayal, P., \& Triplett, C. (2000). The relationship of ethnic identity and ego identity status among adolescents and young adults. International Journal of Intercultural Relations, 24, 777-790.

Cakir, S. G., \& Aydin, G. (2005). Parental attitudes and ego identity status of turkish adolescents. Adolescence, 40(160), 847-885

Dwairy, M. (2004). Internal-structural validity of Objetive Measure of Ego Identity Status among Arab adolescents. Identity, 4(2), 133-144.

Erikson, E. H. (1972). Identidade, juventude e crise. Rio de Janeiro, RJ: Zahar.

Erikson, E. H. (1979). Crescimento e crises. In T. Millon, Teorias da psicopatologia e personalidade (2. ed., pp. 91-104). Rio de Janeiro, RJ: Interamericana.

Erikson, E. H. (1998). O ciclo de vida completo. Porto Alegre, RS: Artes Médicas.

Hoffman, L., Paris, S., \& Hall, E. (1997). Psicología del desarrollo hoy (Vol. 2). Madrid, España: Mcgraw-Hill.

Isquierdo, C. M. (2002). Educar em valores. São Paulo, SP: Paulinas.

Kimmel, D. C., \& Weiner, I. B. (1998). La adolescencia: una transición del desarrollo. Barcelona, España: Ariel.

Kumru, A., \& Thompson, R. A. (2003). Ego identity status and self-monitoring behavior in adolescents. Journal of Adolescent Research, 18(5), 481-495

Lavoie, J. C. (1994). Identity in adolescence: Issues of theory, structure and transition. Journal of Adolescence, 17, 17-28.

Lewis, H. L. (2003). Differences in ego identity among college students across age, ethnicity and gender. Identity, 3(2), 159-189.

Marcia, J. E. (1966). Development and validation of ego identity status. Journal of Personality and Social Psychology, 3, 551-558.

Meeus, W. (1993). Occupational identity development, school performance, and social support in adolescence: Findings of a dutch study. Adolescence, 28(112), 809-818.

Matos, P. M., Barbosa, S., Almeida, H. M., \& Costa, M. E. (1999). Parental attachment and identity in portuguese late adolescents. Journal of Adolescence, 22, 805-818.
Matteson, D. R. (1992). Exploration and commitment: Sex differences and methodological problems in the use of identity status categories. Journal of Youth and Adolescence, 6(4), 353-74.

Schoen-Ferreira, T. H., Aznar-Farias, M. \& Silvares, E. F. M. (2003). A construção da identidade em adolescentes: um estudo exploratório. Estudos de Psicologia 8(1), 107-115.

Schoen-Ferreira, T. H., Meneghelli, N., Veiga-Godoy, Y., \& Aznar-Farias, M. (2005). Validação semântica do Extended Objetive Measure of Ego Identity Status 2 - EOMEIS-2. Desafios para a formação, prática e pesquisa. Paper presented at the meeting of the II Congresso Brasileiro de Avaliação Psicológica, Gramado, RS.

Schwartz, S. J. (2002). Convergent validity in Objective Measures of Identity Status: Implications for identity status theory. Adolescence, 37(3), 609-625.

Schwartz, S. J. (2004). Brief report: Construct validity of two identity status measures: The EIPQ and the EOMEIS-II. Journal of Adolescence, 27(4), 477-483.

Sprinthall, N. A., \& Collins, W. A. (1999). Psicologia do adolescente: Uma abordagem desenvolvimentista (2. ed.). Lisboa, Portugal: Fundação Calouste Gulbenkian.

Stephen, J., Fraser, E., \& Marcia, J. E. (1992). Moratoriumachievement (Mama) cycles in lifespan identity development: Value orientations and reasoning system correlatos. Journal of Adolescence, 15, 283-300.

Tremblay, G., Saucier, J. F., \& Tremblay, R. E. (2004). Identity and disruptiveness in boys: Longitudinal perspectives. Child and Adolescent Social Work Journal, 21(4), 387-406.

Vleioras, G., \& Bosma, H. A. (2005). Are identity styles important for psychological well-being? Journal of Adolescence, 28(3), 397-409.

Waterman, A. S. (1985). Identity in the contexto f adolescent psychology. In A. S. Waterman, Identity in adolescence: Processes and contents: Vol. 30. New directions for child development. San Francisco: Jossey-Bass.

Zacarés, J. J. (1996). Una revisión de las medidas utilizadas en el estudio de la formación de la identidad en la adolescencia. In M. Marín \& F. J. Medina (Eds.), Psicología del desarrollo y de la educación: la intervención psicoeducativa (pp. 251-263). Sevilla, España: Eudema.

Zacarés, J. J., \& Serra, E. (1998). La madurez personal: perspectivas desde la psicología. Madrid, España: Pirámides.
Recebido: $24 / 03 / 2008$

$1^{a}$ revisão: $01 / 07 / 2008$

$2^{a}$ revisão: $15 / 09 / 2008$

Aceite final: $23 / 10 / 2008$ 